\title{
Breaking through restricting bottleneck for better asthma control
}

\author{
Ding Zhu, Chao Zhang, Huahao Shen, Songmin Ying \\ Department of Respiratory and Critical Care Medicine, Second Affiliated Hospital, Institute of Respiratory \\ Diseases, Zhejiang University School of Medicine, Hangzhou, Zhejiang Province, China
}

Asthma is characterized by chronic bronchial inflammation, airway hyperresponsiveness induced by specific and nonspecific stimuli, reversible bronchial obstruction, and airway remodeling. Although standard asthma medications were applied, there are approximately $55 \%$ of patients with asthma still suffer from poorly or uncontrolled disease. ${ }^{[1,2]}$ Uncontrolled asthma is associated with a worse life quality and a higher risk of asthma-related hospitalization and mortality, which results in heavy health care and socioeconomic burden. ${ }^{[3,4]}$ Various factors contribute to the low control rates, such as less responsiveness to pharmacologic therapy, complications of other diseases, incorrect use of inhaler devices, poor medication compliance, and smoking. ${ }^{[5,6]}$ In recent years, a lot of researchers have focused on making new exploratory interventions to improve asthma management and control.

Bronchial thermoplasty (BT) is one of such interventions. According to the stepwise approach to asthma control recommended by Global Initiative for Asthma (GINA) guidelines in 2014 and 2015, BT can be applied in the fifth-level treatment plan. Similar to oral corticosteroids and omalizumab, BT is becoming a routine treatment to patients with severe asthma with persistent symptoms and the evidence was upgraded to level B. BT targets primarily to decrease airway smooth muscle (ASM) by using radiofrequency. As is widely known, ASM play an important pathologic role in airway remodeling. The hypertrophy and hyperplasia of ASM may partly explain the less responsiveness to pharmacologic therapy in patients with uncontrolled asthma. ${ }^{[7,8]}$ So far, several studies have demonstrated significant improvements in clinical asthma outcomes of BT. These improvements mainly includes symptom control, reduction in emergency department visits and hospitalization rates, decreased healthcare cost, improved life quality, reduced dosage of corticosteroids (inhaled or oral) and long-acting beta-agonists (LABA), and reduction in working days or school days lost number. ${ }^{[9-11]}$ Additionally, pooled analysis indicates that BT is well tolerated and demonstrated as an acceptable safety profile in both short- and long-term safety ${ }^{[9,11-13]}$. In summary, BT should be considered as a new treatment option for patients with uncontrolled severe asthma at present. Further well-designed randomized clinical trials need to concentrate more on patient selection so that the work could be targeted on potentially benefited subgroups.

In the population of uncontrolled asthmatics, the existence of associated comorbidities may disrupt the effect of asthma-related therapy and limit asthma symptom control. These comorbidities, which includes postnasal drip, allergic rhinitis (AR), nasal polyps, gastroesophageal reflux disease, and obstructive sleep apnea (OSA), are well accepted as inducing factors of asthma. Although standard therapy was taken, asthma would not also be well controlled and may easily reoccur if these disorders could not be cured, even leading to difficulty in performing de-escalation therapy. Therefore, to this special population with asthma, we recommend to develop individualized treatment strategies as proposed by GINA 2014. For example, AR and asthma were regarded as "one airway, one disease." ${ }^{[14]}$ Previous studies demonstrated that among patients with asthma and concomitant AR, 
Zhu et al.: Better control of asthma

those who were treated for AR had a significantly lower risk of subsequent asthma-related events (emergency department visits/hospitalizations) ${ }^{[15]}$. Thus, combined therapy in the both upper and lower respiratory tracts are recommended in patients with asthma and AR. Similarly, although OSA can increase the risk for worse asthma control in patients complicated with asthma, the CPAP therapy have great impact on asthma outcomes. ${ }^{[16]}$ As a result, CPAP and standard anti-asthma therapy should be combined in these patients.

Finally, as a chronic disease, the asthma management and follow-up are issues that cannot be neglected. During drug inhalation, the usage and dosage/frequency of medications are cornerstones of successful treatment. Unfortunately, it has been reported that the overall prevalence of correct inhaler technique was only $31 \%$, on an average $e^{[17]}$. Hence, incorrect usage of inhaler devices and poor medication adherence were the main causes of treatment failure and low control rates in patients with asthma. In this case, patient education seems to be particularly important. However, traditional patient education for out-patients is often limited to clinics, usually leading to poor selfmanagement and medication compliance. Many patients could not correctly understand and master the usage of inhaler devices within a short period of clinic visit time. Thus, they experience relatively lower treatment efficacy. To resolve this dilemma, in recent years, positive interventions including video of using inhaler devices, pharmacist telephone, electronic monitoring, and public platforms such as WeChat are used instead of text message and booklet were used as educational and follow-up measures to educate and instruct patients with asthma. ${ }^{[18-20]}$ Using these novel interventions as part of treatment and asthma management, not only the disease control and therapy effects have been improved, but also public awareness of asthma diseases and medications have been increased.

With the progress and efforts of the above aspects, we believe that the bottleneck for asthma control will be broken through soon. Therefore, better control rate of asthma will be achieved.

\section{Conflict of Interest}

None declared.

\section{REFERENCES}

1. Peters SP, Jones CA, Haselkorn T, Mink DR, Valacer DJ, Weiss ST. Real-world Evaluation of Asthma Control and Treatment (REACT): findings from a national Web-based survey. J Allergy Clin Immunol 2007; 119: 1454-61.

2. Rijavec M, Korosec P, Zavbi M, Kern I, Malovrh MM. Let-7a is differentially expressed in bronchial biopsies of patients with severe asthma. Sci Rep 2014; 4: 6103.
3. Chipps BE, Zeiger RS, Dorenbaum A, Borish L, Wenzel SE, Miller DP, et al. Assessment of asthma control and asthma exacerbations in the epidemiology and natural history of asthma: outcomes and treatment regimens (TENOR) observational cohort. Curr Respir Care Rep 2012; 1: 259-69.

4. Peters SP, Ferguson G, Deniz Y, Reisner C. Uncontrolled asthma: a review of the prevalence, disease burden and options for treatment. Respir Med 2006; 100: 1139-51.

5. Apikoglu-Rabus S, Yesilyaprak G, Izzettin FV. Drug-related problems and pharmacist interventions in a cohort of patients with asthma and chronic obstructive pulmonary disease. Respir Med 2016; 120: 109-15.

6. Plaza V. Update on questionnaires for assessing adherence to inhaler devices in respiratory patients. Curr Opin Allergy Clin Immunol 2017. doi: 10.1097/ACI.0000000000000410

7. Vignola AM, Mirabella F, Costanzo G, Di Giorgi R, Gjomarkaj M, Bellia V, et al. Airway remodeling in asthma. Chest 2003; 123(3 Suppl): S417-22.

8. Mitzner W. Airway smooth muscle: the appendix of the lung. Am J Respir Crit Care Med 2004; 169: 787-90.

9. Zhou JP, Feng Y, Wang Q, Zhou LN, Wan HY, Li QY. Long-term efficacy and safety of bronchial thermoplasty in patients with moderate-to-severe persistent asthma: a systemic review and meta-analysis. J Asthma 2016; 53: $94-100$.

10. Thomson NC, Rubin AS, Niven RM, Corris PA, Siersted HC, Olivenstein $\mathrm{R}$, et al. Long-term (5 year) safety of bronchial thermoplasty: Asthma Intervention Research (AIR) trial. BMC Pulm Med 2011; 11: 8.

11. Castro M, Rubin AS, Laviolette M, Fiterman J, De Andrade Lima M, Shah PL, et al. Effectiveness and safety of bronchial thermoplasty in the treatment of severe asthma: a multicenter, randomized, double-blind, sham-controlled clinical trial. Am J Respir Crit Care Med 2010; 181: 116-24.

12. Cox G, Thomson NC, Rubin AS, Niven RM, Corris PA, Siersted HC, et al. Asthma control during the year after bronchial thermoplasty. $\mathrm{N}$ Engl J Med 2007; 356: 1327-37.

13. Pavord ID, Cox G, Thomson NC, Rubin AS, Corris PA, Niven RM, et al. Safety and efficacy of bronchial thermoplasty in symptomatic, severe asthma. Am J Respir Crit Care Med 2007; 176: 1185-91.

14. Grossman J. One airway, one disease. Chest 1997; 111(2 Suppl): S11-6.

15. Crystal-Peters J, Neslusan C, Crown WH, Torres A. Treating allergic rhinitis in patients with comorbid asthma: the risk of asthma-related hospitalizations and emergency department visits. J Allergy Clin Immunol 2002; 109: 57-62.

16. Teodorescu M, Polomis DA, Gangnon RE, Fedie JE, Consens FB, Chervin $\mathrm{RD}$, et al. Asthma Control and Its Relationship with Obstructive Sleep Apnea (OSA) in Older Adults. Sleep Disord 2013; 2013: 251567.

17. Levy ML, Dekhuijzen PN, Barnes PJ, Broeders M, Corrigan CJ, Chawes $\mathrm{BL}$, et al. Inhaler technique: facts and fantasies. A view from the Aerosol Drug Management Improvement Team (ADMIT). NPJ Prim Care Respir Med 2016; 26: 16017.

18. Gregoriano C, Dieterle T. Impact of an Electronic Monitoring Intervention to Improve Adherence to Inhaled Medication in Patients with Asthma and Chronic Obstructive Pulmonary Disease: Study Protocol for a Randomized Controlled Trial. 2017; 6: e204.

19. Niznik JD, He H, Kane-Gill SL. Impact of clinical pharmacist services delivered via telemedicine in the outpatient or ambulatory care setting: A systematic review. Res Social Adm Pharm 2017. doi: 10.1016/j.sapharm.2017.10.011

20. Brown S, Lehr VT, French N, Giuliano CA. Can a Short Video Improve Inhaler Use in Urban Youth? J Pediatr Pharmacol Ther 2017; 22: 293-9.

How to cite this article: Zhu D, Zhang C, Shen H, Ying S. Breaking through restricting bottleneck for better asthma control. J Transl Intern Med 2017; 5: 192-93. 